\title{
Investigation of Polyaniline Thin Film and Schottky Junction with Aluminium for Electrical and Optical Characterization
}

\author{
Pronob Jyoti Saikia, Pratap Chandra Sarmah* \\ Department of Electronics, North-East Institute of Science and Technology, Jorhat, India. \\ Email: pratap_sarmah@yahoo.com, ${ }^{*}$ sarmahpc@neistjorhat.res.in \\ Received April 1 $1^{\text {st }}$ 2011; revised May 6 ${ }^{\text {th }}$, 2011; accepted May 23 ${ }^{\text {rd }}, 2011$
}

\begin{abstract}
Polyaniline Powdered sample was chemically synthesized using aniline and doped with HCl. Ultra thin film and Schottky junction with Al metal have been fabricated from this powdered sample Ultrathin film of polyaniline shows amorphous nature of the film. Two activation energies of these films at two different temperatures regions within $25-120^{\circ} \mathrm{C}$ have been observed. Schottky Junction with Al metal shows that the diode ideality factor is much higher than unity. Barrier height of this Schottky junction is estimated to be around $0.61 \mathrm{eV}$. C-V plot of the junction indicates that the carrier concentration is about $10^{15} \mathrm{~cm}^{-3}$. There are various factors found to affect the junction to deviate from ideal Schottky behaviour.
\end{abstract}

Keywords: Aniline, Activation Energy, Diode Ideality Factor, Barrier Height

\section{Introduction}

Among all conducting polymers, polyaniline (PANI) and its derivatives have attracted much interest worldwide. Because of chemical stability, simple polymerization, high conductivity, polyaniline has been used in various application, like, optoelectronics, bio-sensors, gas sensors, microelectronics etc. [1-5]. Several methods of preparation of PANI film such as, spin coating, drop coating, electrochemical deposition, thermal evaporation, emulsion polymerization, Langmuir-Blodgett (L-B) technique etc. [6-11] have been reported by various workers. Polyaniline may be doped by protonic acid and oxidative doping [12]. It has been reported that the conductivity of film cast from solution of polyaniline camphor sulphonate in m-cresol is of about 2 order of magnitude higher than that of polyaniline protonated with mineral acid and organic acid [13]. Different inorganic and organic acids of different concentration have been used in the synthesis of PANI and this protonated products of polyaniline differs in stability and conductivity [14]. The effect on property and growth of polyaniline produced by ionic sputtering in presence of electric and magnetic field was studied by P. Stakhria et al. [15]. Nanocomposite of PANI is an important candidate for device application in biosensor, gas sensors, optoelectronics etc. [16-19].
Schottky junction of polyaniline with metal is another important subject and have great technological importance [20]. This is recently gaining momentum for device application. Electrical and optical properties of polyaniline and its composite is however dependent on preparation techniques and matrix material used [21]. The aim of this study is to see the various properties of the ultra thin film and Schottky junction of $\mathrm{HCl}$ doped PANI and to improve the quality for device fabrication. In the process, we have prepared powered polyaniline by chemical synthesis method and produced ultra thin films by simple technique. Electrical and optical properties of these films and Schottky junctions with $\mathrm{Al}$ metal have been investigated.

\section{Experimental}

\subsection{Preparation of Polyaniline Powder}

Chemical Synthesis of polyaniline in the form of emaraldine salt was done by the general procedure using redox polymerization of aniline in presence of an oxidant, ammonium peroxidisulphate (APS) and using $\mathrm{HCl}$ as dopant. Freshly distilled aniline $(4 \mathrm{ml})$ in $50 \mathrm{ml}$ of $1 \mathrm{M}$ $\mathrm{HCl}$ solution at 2 to $3^{\circ} \mathrm{C}$ was stirred for 20 minutes and subsequently added 1M APS solution (25 ml) drop wise at a rate of 5 drops/minutes. The process continued till 
the whole quantity was added and the solution turned green. Stirring of the compound continued for about 3 hours after which the solution was kept for overnight. The precipitate was treated with Tetrahydroforen to eliminate other oligomers and was filtered using funnel. The product was dried in an oven for 24 hours at $45^{\circ} \mathrm{C}$ to get the powder.

\subsection{Preparation of the Film and Junction}

The powdered sample of PANI was dissolved in Dimethyl Sulfoxide (DMSO) in a beaker with continuous stirring for about 4 hours. The solution was filtered and drops of it were placed over a glass slide already cleaned by chemical wash and subsequently in ultrasonic bath. The drops were spread over by small glass spoon to make in the form of film. For fabrication of junction, ITO coated glass substrate were used after proper cleaning. This was dried in a specially made vacuum chamber which was fitted with a heater and a temperature controller. The temperature was maintained at $45^{\circ} \mathrm{C}$ for drying in vacuum for about 5 hours. Four sets of ultrathin films in the ranges from $200 \AA$ to $400 \AA$ were produced in a cycle to study various parameters. One set of film so produced was taken to the thermal evaporation unit for deposition of electrodes. Gap type sample was made by using two co-planer electrodes separated by a gap to study electrical properties. Two electrodes of pure silver were deposited onto the film keeping a gap of $1 \mathrm{~mm}$ using a mask. For fabrication of junction, high purity $\mathrm{Al}$ foil (99.99\% purity) was vacuum deposited onto the film that was already prepared over the ITO coated glass slide in the form of small disc shaped electrodes. The schematic diagrams of gap type and sandwich type structure are shown in Figure 1.

\subsection{Experimental Arrangement}

The samples of polyaniline film and junction so prepared were kept in a departmentally designed vacuum chamber for studying different characteristics. It is a glass cylindrical chamber of $35 \mathrm{~cm}$ length and $14 \mathrm{~cm}$ in diameter. It is fitted with some electrical feedthroughs for electrical and temperature controlling arrangement and a has gas inlet valve. The chamber could be evacuated by a rotary pump. All measurements were carried out in this chamber keeping the sample in vacuum.

The structural investigation of the powered Polyaniline and film so prepared was done by XRD spectrometer (JDX-IIP3A). Absorption spectra was taken by a UV-Vis spectrometer (Specord-200). IR absorption was recorded by a fourier Transform spectrometer (Perkin Elmer System 2000). Electrical characteristics were measured by a electrometer amplifier using two probe method. The temperature effect was measured in the chamber as mentioned above at a vacuum of $10^{-4}$ torr.

\section{Results and Discussions}

\subsection{For the Films}

XRD spectra of the powdered and thin film samples show nearly amorphous nature of the samples (Curve A of Figure 2). However, with increase of thickness, the film grows in grains and at higher thickness, the films tends to be polycrystalline in nature. The PANI peak at around $2 \theta=9.5^{\circ}$ has been indicted in the curve B of Figure 2. Similar observation has also been reported by other workers [22] in PANI film. Figure 3 shows the FT-IR spectra of PANI film. As is seen from the figure, the peaks around $1563 \mathrm{~cm}^{-1}$ and $1476 \mathrm{~cm}^{-1}$ correspond to the absorption upon quinoid ring and is closed to that corresponding to the absorption of benzene ring $\left(1502 \mathrm{~cm}^{-1}\right)$. The peak around $1470 \mathrm{~cm}^{-1}$ can be attributed to torsion C-N oscillation in Alkyl chain and peak at $1301 \mathrm{~cm}^{-1}$ to torsion oscillation C-N in the Benzene ring. The peak at $1119 \mathrm{~cm}^{-1}$ can be attributed to in plane valance oscillation C-H. UV-Vis spectra (Figure 4) indicates the absorption peaks at $3.8 \mathrm{eV}$ and $4.1 \mathrm{eV}$ of doped polyanilene and these can be attributed to the transition from lower polaron to upper polaron and to the conduction band respectively [23].

A plot of conductivity $\sigma$ versus $10^{3} / \mathrm{T}$ for the film in the range of $25^{\circ} \mathrm{C}$ to $120^{\circ} \mathrm{C}$ (Figure 5) of a typical sample shows that conductivity increases with temperature within this range.

The conductivity may be express as :

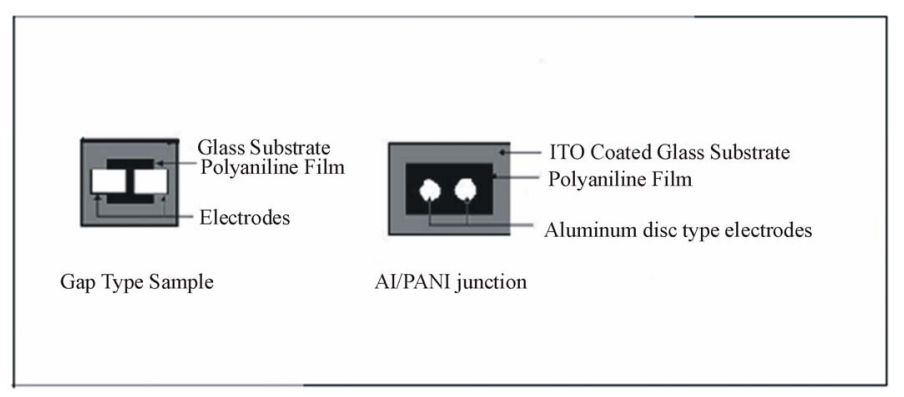

Figure 1. Sample for measurement. 


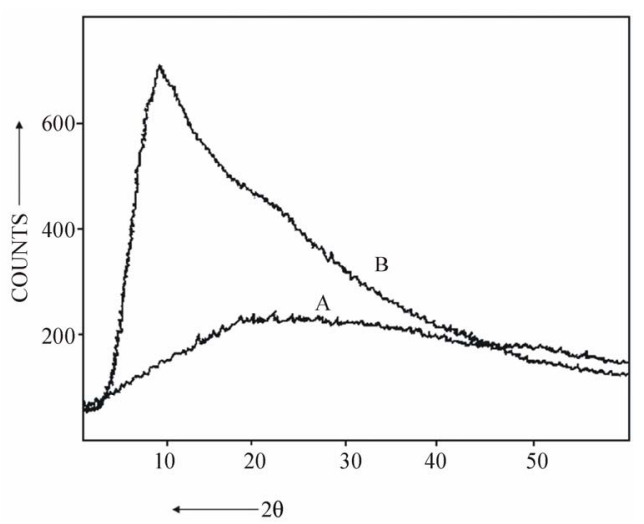

Figure 2. XRD spectra of HCl doped PANI film. (A) Thin film of PANI (B) Thick film of PANI.

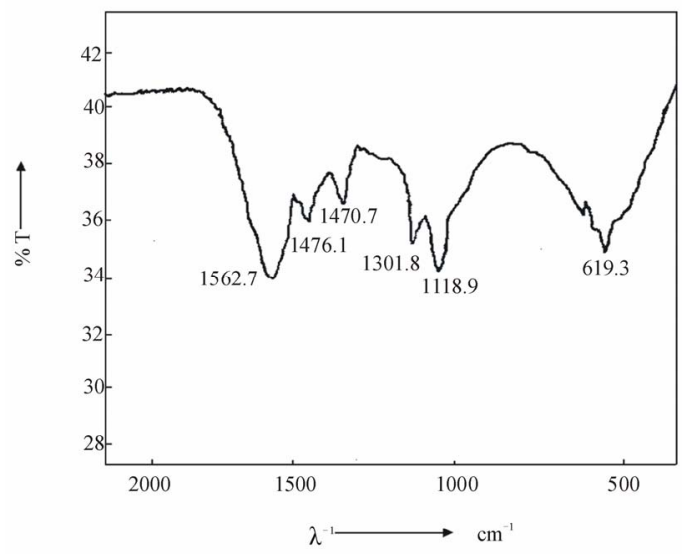

Figure 3. FTIR spectra of a typical doped film of PANI.

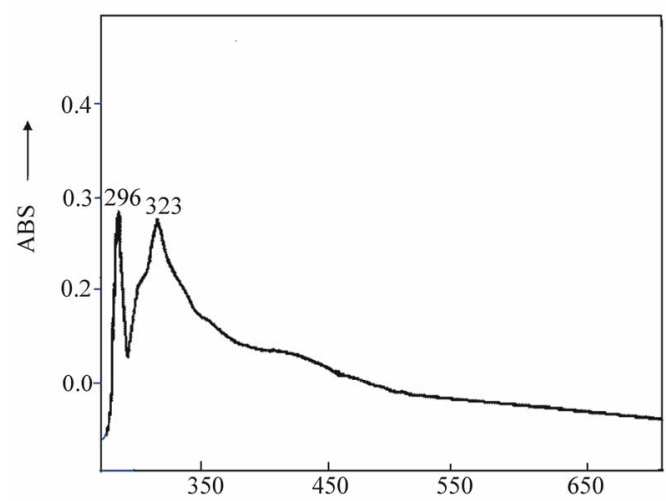

Figure 4. UV-Vis spectra of the doped film of PANI.

$$
\boldsymbol{\sigma}=\boldsymbol{\sigma}_{\mathbf{0}} \operatorname{Exp}\left(-\mathbf{E}_{\mathbf{a}} / \mathbf{k} \mathbf{T}\right)
$$

where, $\boldsymbol{\sigma}_{\mathbf{0}}$ is pre exponential factor, $\mathbf{k}, \mathbf{T}$ and $\mathbf{E}_{\mathbf{a}}$ are the Boltzmann constant, absolute temperature and activation energy respectively. The conductivity may be attributed to hopping conduction model where two types of conductivity components are combined such that $\boldsymbol{\sigma}$ can be written as:

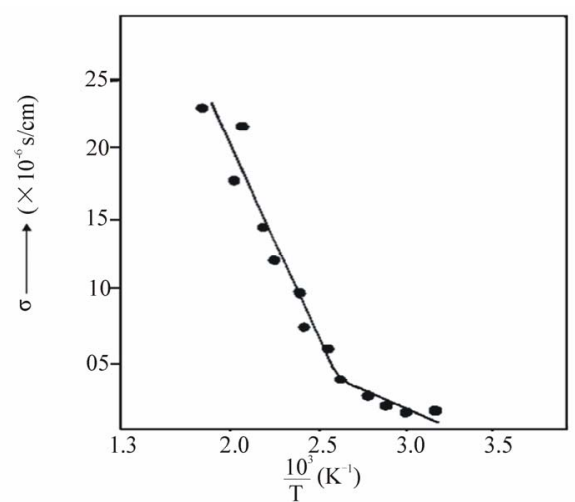

Figure 5. The Temperature versus Conductivity pl ot of typical doped PANI film.

$$
\boldsymbol{\sigma}=\sigma_{1}+\sigma_{2}
$$

where, $\boldsymbol{\sigma}_{\mathbf{1}}$ and $\boldsymbol{\sigma}_{\mathbf{2}}$ are inter chain and intra chain respectively. Activation energy estimated in the lower temperature range is about $0.5 \mathrm{eV}$ and at higher temperature is about $3.5 \mathrm{eV}$. Similar observations in polyaniline film have been reported by previous workers [24-25]. Yakuphanoglu et al. [26] have reported three regions for temperature variation of resistivity in polyaniline film.

\subsection{For the Junction}

Al/PANI/ITO junction was fabricated as mentioned above for studying various parameters. The junction produced by $\mathrm{Al}$ on doped PANI film shows rectifying nature of the junction (Figure 6). ITO with high work function make ohmic contact to PANI (p-type). The current density $\mathbf{J}$ and voltage $\mathbf{V}$ can be expressed by the Richardson's equation as,

$$
\mathbf{J}=\mathbf{J}_{\mathbf{0}} \operatorname{Exp}(\mathbf{q V} / \mathbf{k T})
$$

where $\mathbf{J}_{\mathbf{0}}$ is the saturation current density and can be written as :

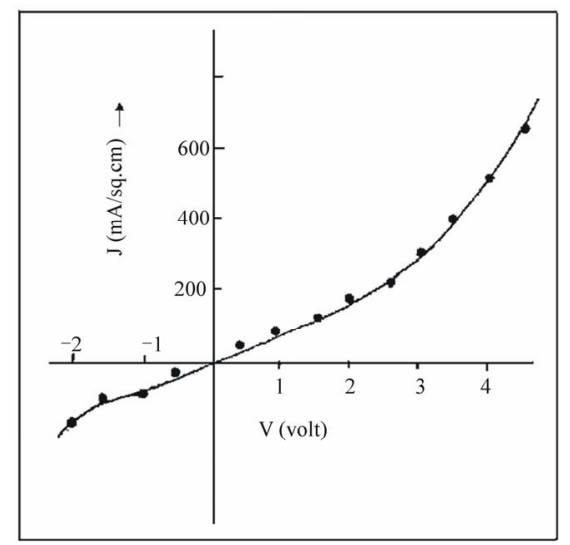

Figure 6. Current density versus Voltage characteristics of the AI/PANI/ITO structure. 


$$
\mathbf{J}_{\mathbf{0}}=\mathbf{A}^{*} \mathbf{T}^{2} \operatorname{Exp}\left(-\boldsymbol{\emptyset}_{\mathbf{b}} / \mathbf{k T}\right)
$$

where $\mathbf{A}^{*}$ and $\boldsymbol{\emptyset}_{\mathbf{b}}$ are the Richardson constant and effective barrier height respectively. The saturation current density is estimated to be around $5.4 \times 10^{-3} \mathrm{~A} / \mathrm{sq} \cdot \mathrm{cm}$. $\mathbf{C}^{-2}-\mathbf{V}$ plot under reverse bias condition at $10 \mathrm{KHz}$ has been shown in Figure 7. The plot of the junction shows almost a linear relationship indicating the average uniform charge distribution in the space charge region. The carrier concentration estimated from the slope is found to be around $10^{15} \mathrm{~cm}^{-3}$. The diffusion potential $\mathbf{V}_{\mathbf{0}}$ obtained from the graph is around $0.58 \mathrm{eV}$. Barrier height estimated from the saturation current density $\mathrm{J}_{0}$ using $\mathbf{A}^{*}$ value as $120 \mathrm{AK}^{-2} \cdot \mathrm{cm}^{-2}$ is found to be $0.61 \mathrm{eV}$. This value is however almost agree with the value of $0.6 \mathrm{eV}$ derived from the diffusion potential after necessary correction. Wei-chih chen et al. have also reported similar barrier height for Al/PANI junction [27]. The barrier height above $1.5 \mathrm{eV}$ for boron trifloride doped PANI with $\mathrm{Al}$ metal has been also reported [28].

The diode ideality factor $\mathbf{n}$ of these junctions are higher than unity. An estimate of diode ideality factor shows to be around 8 . The various factors responsible for diode ideality factor greater than unity are, presence of an interfacial layer, recombination of charges, migration of electrode materials etc. One possible cause is the presence of the aggregation of primary and secondary particles arising during polymerization giving rise to two different transport mechanisms [29]. Recombination in the depletion region is another possible cause. This also contributes to the fact that reverse current is not showing saturation. Presence of a very thin interfacial layer is not ruled out. This is formed while transferring the film to a vacuum evaporation chamber for depositing the counter electrode. Similar affect of interfacial layer and effect on diode ideality factor have been reported by earlier worker in metal/polymer junction [30]. Since the car-

rier concentration is moderate, the current transport is

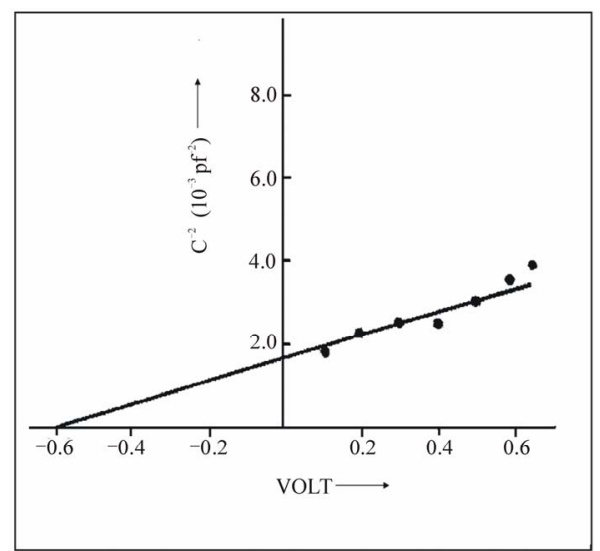

Figure 7. Voltage versus Capacitance plot of the junction of figure 6. mainly dominated by the thermionic emission process. Similar observations on Al/PANI junction have also reported by previous workers [31].

\section{Conclusions}

Thin film of $\mathrm{HCl}$ doped PANI and Schottky junction with $\mathrm{Al}$ have been fabricated. Ultra thin film of PANI produced in this process is amorphous in nature. The UV-Vis spectra indicate the two transitions peaks. The film shows two activation energies at $0.5 \mathrm{eV}$ and $3.5 \mathrm{eV}$ at two temperatures regions respectively. PANI film makes Schottky junction with $\mathrm{Al}$ and has high ideality factor. The barrier height obtained for the junction is around $0.6 \mathrm{eV}$. The current transport is believed to be mainly dominated by thermionics emission process.

\section{Acknowledgements}

The authors wish to thank the Director, NEIST, Jorhat for providing necessary facilities to carry out this work.

\section{REFERENCES}

[1] M. K. Ram, O. Yang, V. Lahsangarh and M. Aldissi, “CO Gas Sensing from Ultrathin Nano-Composite Conducting Polymer Films," Sensors and Actuators B, Vol. 106, 2005, pp. 750-757. doi:10.1016/j.snb.2004.09.027

[2] G. Liu and M. S. Freund, "New Approach for the Controlled Cross-Linking of Polyaniline: Synthesis and Characterization,” Macromolecule, Vol. 30, No. 19, 1997, pp. 5660-5665. doi:10.1021/ma970469n.

[3] S. Koul, R. Chandra and S. K. Dhawan, "Conducting Polyaniline Composite: a Reusable Sensor Material for Aqueous Ammonia,” Sensors and Actuators B: Chemical, Vol. 75, No. 3, 2001, pp. 151-159. doi:10.1016/S0925-4005(00)00685-7

[4] N. Takami, A. Satoh, M. Hara and T. Ohsaki, "Structural and Kinetic Characterization of Lithium Intercalation into Carbon Anodes for Secondary Lithium Batteries," Journal Electrochemical Socience, Vol. 142, 1995, pp. 371379. doi:10.1149/1.2044017

[5] J. Stejskal, P. Kratochvil and A. D. Jenkins, "The Formation of Polyaniline and the Nature of Its Structures," Polymer, Vol. 37, No. 2, 1996, pp. 367-369. doi:1016/0032-3861(96)81113-X

[6] G. K. Prasad, T. P. Radhakrishnan, D. S. Kumar and M. G. Krishna, "Ammonia Sensing Characteristics of Thin Film Based on Polyelectrolyte Templated Polyaniline," Sensors and Actuators B: Chemical, Vol. 106, No. 2, 2005, pp. 626-631. doi:10.1016/J. sub.2004.09.011.

[7] L. Ruangchuay, A. Sirivat and J. Schwank, "Selective Conductivity Response of Polypyrrole-based Sensor on Flammable Chemicals," Reactive and Functional Polymer, Vol. 61, No. 1, 2004, pp. 11-22. doi:10.1016/j.reactfunctpolym.2004.03.004

[8] G. W. Lu, L. T. Qu and G. Q. Shi, "Electrochemical Fabrication of Neuron-type Networks Based on Crystalline 
1026 Investigation of Polyaniline Thin Film and Schottky Junction with Aluminium for Electrical and Optical Characterization

Oligopyrene Nanosheets,” Electrochimica Acta, Vol. 51, No. 2, 2005, pp. 340-346.

doi:10.1016/i.electacta-2005.04.043

[9] N. E. Agbor, M. C. Petty and A. P. Monkman, "Polyaniline Thinfilm for Gas Sensing," Sensors and Actuators B: Chemical, Vol. 28, No. 3, 1995, pp. 173-179. doi:10.1016/0925-4005(95)01725-9.

[10] Z. Mo, W. Qui, X. C. Yang and J. Yan, "Morphological Characterization and Kinetics Study of Polyaniline Film Formation by Emulsion Polymerization," Journal of Polymer Research, Vol. 16, No. 1, 2009, pp. 39-43. doi:10.1007/s10965-008-9200-8

[11] J. H. Cheung, A. F. Fou and M. F. Rubner, "Molecular Self Assembly of Conducting Polymer," Thin solid Films, Vol. 84, No. 1-3, 1994, pp. 985-989. doi:10.1016/0040-6090(94)9061-5

[12] M. Menon, C. G. Yoon, D. Moses and A. J. Heeger, "Handbook of Conductive Polymers," T. A. Skotheim, R. L. Elsenbanmer and J. R. Reynold (Ed.), Marcel Dekker, New York, 1998.

[13] J. Stejskal and I. Sepuria, "Solid State Protonation and Electrical Conductivity of Polyaniline," Macromolecule, Vol. 31, No. 7, 1998, pp. 2218-2222. doi:10.1021/ma970823h

[14] D. C. Trivedi, "Hand Book of Organic Conductive Molecules and Polymer," John Wiley \& Sons Limited, Vol. 2, No. 1, 1997, p 505.

[15] P. Stakhira, V. Cherpak, D. Volynyuk, Z. Hotra, V Belukh, O. Aksimentyeva, B. Tsizh and L. Monastyrskyi, "Growth and Properties of Conducting Polyaniline Thin Films Obtained by Means of Ionic Sputtering in Crossed Electrical and Magnetic Field,” Review Advance Material Science, Vol. 23, 2010, pp. 180-184.

[16] X. He and W. Qi, "Ultrasonic Irradiation: A Noval Approach to Prepare Conductive Polyanuline/Nanocrystalline Titanium Oxide Composites," Chemistry Material, Vol. 14, No. 5, 2002, pp. 2158-2165. doi:10.1021/cm0109591

[17] B. Kim, J. Jae, H. Seung and J. Jinsoo, "Nanocomposite of Polyaniline and $\mathrm{Na}^{+}$-Montmorillonine Clay," Macromolecule, Vol. 35, No. 4, 2002, pp. 1419-1423. doi:10.1021/ma010497c

[18] P. G. Hill, J. Peter, S. Fort and R. Devis, "Novel Inorganic/Conjugated Polymer Nano-Composites," Synthetic Metals, Vol. 76, No. 1-3, 1996, pp. 289-292. doi:10.1016/ 0379- 6779 (95)03473-w

[19] H. Yang, T. D. Chung, Y. T. Kim, C. A. Choi, C. H. Jun and H. C. Kim, "Glucose Sensor Using a Micro Fabricated Electrode and Electropolymerized Bilayer Films," Biosensors and Bioelectronics, Vol. 17, pp. 251-259. doi:10.1016/S0958-5663(01)00266-4

[20] Assadi, C. Svensson, M. Willander and O. Inganas, "Properties of the Planar Poly (3-octylthiophene)/Aluminum Schottky Barrier Diode," Journal of Applied Physics, Vol. 72, No. 7, 1992, pp. 2900-2908. doi:10.1063/1.351491
[21] Pud, N. Ogurtsov, A. Korzhenko and G. Shapval, “Some Aspects of Preparation Methods and Properties of Polyaniline Blends and Composites with Organic Polymers," Progress in Polymer Science, Vol. 28, No. 12, 2003, pp. 1701- 1753. doi:10.1016/j.progpolymsci.2003.08.001

[22] H. K. Chandhuri and D. S. Kelkar, "X-ray Diffraction Study of Doped Polyaniline,” Journal of Applied Polymer Science, Vol. 62, 1996, pp. 15-18. doi:10.1002/ (SICI) 1097-4628(19961003)

[23] E. A. de Vasconcelos, E. F. da Silva Jr., J. M. G Laranjeira, W. M. de Azevedo, I. M. Pepe and A. F. da Silva, "Oplical and Electrical Characterization of the Band Structure of Polyaniline Nanofilms and Polyaniline/ Silicon Hefereojunctions,” Physica Status Solid C, Vol. 2, No. 8, 2005, pp. 2482-2985. doi:10.1002/PSSC. 200460-725

[24] F. Yakuphanoglu, B. F. Senkal and A. Sarac, "Electrical Conductivity, Temperature Power, and Optical Properties of Organo-Soluble Polyaniline Organic Semiconductor," Journal of Electronic Materials, Vol. 37, No. 6, 2008, pp. 930-934. doi:10.1007/s 11664-008-0404-9

[25] H. Devendrappa, U. V. Subba Rao and M. V. N. Ambika Prasad, "Study of Dc Conductivity and Battery Application of Polyethylene Oxide/ Polyaniline and Its Composites,” Journal of Power Sources, Vol. 155, No. 2, 2006 pp. 368-374. doi:10.1016/J. Jpowsour 2005.50.014

[26] F. Yakuphanoglu and B. F. Senkal, "Electronic and Thermoelectric Properties of Polyaniline Organic Semiconductor and Electrical Characterization of Al/PANI MIS Diode,” Journal Physical Chemistry C, Vol. 111, 2007, pp. 1840-1846. doi:10.1021/jp0653050

[27] C. C. Wei, T. C. Wen and A. Gopalan, "Fabrication and Charactcuzation of schottlcy Junctions of Aluminium with Polyaniline Containing Hydrolysis Products," Journal of Electrochemical Society, Vol. 151, No. 10, 2004, pp. F242-F247. doi:10.1149/1.1795255

[28] F. Yakuphanoglu and B. F. Senkal, "Current-Voltage and Capacitance-Voltage Characteristics of the ITO/Polyaniline Doped Boron Trifloride/Al Schottly Diode," Polymers for Advanced Technologies, Vol. 19, No. 12, 2008, pp 1882-1886. doi:10.1002/pat.1223

[29] S. Angappane, N. Rajeev Kimi, T. S. Natarajan, G. Rangarajan and B. Wessling, "Pani-PMMA Lend/Metal Schottly Barriers,” Thin Solid Films, Vol. 417, No. 1-2, 2002, pp. 202-205. doi:10.1016/50040-6090(02) 00576-X.

[30] Bantikassegn and O. Inganas, "Electronic Properties of Junctions between Aluminum and Doped Poly (3, 4-Ethylenediony Thiophone)," Thin Solid Films, Vol. 293, No. 1-2, 1997, pp. 138-143. doi:10.1016/50040-6090(96) 08959-4

[31] R. Gupta, S. C. K. Mishra, B. D. Malhotra, N. N. Beladakere and S. Chandra, "Metal/ Semiconductive Polymer Schottky Device,” Applied Physics Letters, Vol. 58, 1991, pp. 51-53. doi:10.1063/1.104441. 